Original Research Paper

\title{
Phylogeny and Molecular Study of Some Entomopathogenic Rhizobacteria Isolated from Two Regions in Algeria
}

\author{
${ }^{1}$ Oulebsir-Mohandkaci Hakima, ${ }^{1}$ Benzina Farida, \\ ${ }^{2}$ Khemili-Talbi Souad, ${ }^{1}$ Mohammedi Arezki, ${ }^{1}$ Halouane Fatma and ${ }^{1}$ Hadjouti Ryma \\ ${ }^{1}$ Laboratoire de Conservation et Valorisation des Ressources Biologiques (VALCORE), \\ Faculté des Sciences, Université M'Hamed Bougara de Boumerdès, Avenue de l'indépendance, Boumerdès 35 000, Algeria \\ ${ }^{2}$ Département de Biologie, Faculté des Sciences, Université M'Hamed Bougara de Boumerdès, Avenue de l'indépendance, \\ Boumerdès 35 000, Algeria
}

Article history

Received: 25-12-2019

Revised: 11-02-2020

Accepted: 29-02-2020

Corresponding Author: Oulebsir-Mohandkaci Hakima Laboratoire de Consevation et Valorisation des Ressources Biologiques (VALCORE), Faculté des Sciences, Université M'Hamed Bougara de Boumerdès, Avenue de l'indépendance, Boumerdès 35 000, Algeria

Tell: 00213772501934

Email: mohandkacihakima@yahoo.fr

\begin{abstract}
The use of bacteria in the control of insect pests is a form of biological control whose practice is still not widespread. It is in this context that the present work falls. It concerns the isolation, characterization and identification of local bacterial strains for the purpose of their use in the control of certain pests. Indeed, 20 bacteria were isolated from soil cultivated in the region of Boumerdes (center of Algeria) with a total of 21 bacterial strains isolated from Adrar region (Desert Algerian). After carrying out the efficacy tests against 2 insect pests; Migratory locust (Locusta migratoria) and wax moth (Galleria mellonella), 8 potentially interesting strains were identified based on their genetic traits. Molecular characterization of these strains was performed by isolation of DNA, PCR and sequencing of the $16 \mathrm{~S}$ rRNA gene, followed by phylogenetic analysis. The rDNA16S sequences of the 8 strains named B1, B2, B3, B4, B5, B6, $\mathrm{H} 1$ and $\mathrm{H} 2$ were recorded in the EMBL/EBI database and their phylogenetic analysis revealed that they belong to the genera Bacillus, Pseudomonas, Enterobacter and Delftia with a very high percentage of similarity with Bacillus thuringiensis strains (NR_043403) (99\%) for isolate B1, Bacillus weihenstephanensis (NR_024697) (99\%) for isolate B2, Pseudomonas fragi (JCM5420) (99\%) for isolates B3 and B4, Bacillus thuringiensis (CMBLBT-5) (99\%) for isolate B4, Enterobacter ludwigii (EN-119) for B5, Bacillus thuringiensis (4916) (99\%) for isolate H1 and Delftia lacustris (R-54734) (100\%) for isolate H2.
\end{abstract}

Keywords: Isolation, Entomopathogenic Bacteria, Rhizosphere, Molecular Identification, Phylogeny, MEGA6.06

\section{Introduction}

Due to the use of a large amount of chemical products, continuous loss of soil fertility puts pressure on farmers toward more crop production in a sustainable manner. Therefore, it requires adapting an eco-friendly, sustainable and cost-effective approach for agricultural practices without arising environmental issues (Singh et al., 2019).

Indeed, the soil is a reservoir of numerous microorganisms critical for the sustainable functioning of natural and managed ecosystems (Sharma et al., 2019). Several natural rhizobacteria inhabiting the rhizospheric soil exist, their application reduces the utilization of chemical fertilizers, pesticides and other artificial growth regulators that cause severe health and environmental issues, soil infertility, water pollution and biodiversity losses (Singh et al., 2019).
Multiple species of entomopathogenic bacteria may be isolated from this part of soil, they are the enemies of pest-insects, whose utility in agroecosystems has been studied since decades. These entomopathogens spend significant time period in soil, either as saprotrophs, resting spores or dormant endospores (OulebsirMohandkaci et al., 2016; Sharma et al., 2019).

Among the key insect-pest in Algeria, Locusta migratoria (Orthoptera-Acrdidae) and Galleria mellonela (Lepidoptera-Pyralidae) exhibit different damage to agriculture and are distributed in all the country (Oulebsir-Mohandkaci et al., 2016; Benzina et al., 2017). With increased awareness towards the environment, biological methods to control these two pests such as biopesticides based on entomopathogenic have been receiving greater attention as alternatives to chemicals pesticides (Jaronski, 2010). 
To facilitate the isolation of entomopathogenic strains from soil, insect baiting by Galleria mellonella or the 'Galleria-bait method' (Zimmermann 1986; Benzina et al., 2017), is the most renowned methodology. The migratory locust was also used for this. The main advantage of the insect baiting method is that only entomopathogens are obtained selectively amongst other soil microbes (Vega et al. 2012; Sharma et al., 2018).

\section{Material and Methods}

\section{Sol Sampling}

The soil samples were taken from Adrar region in the Algerian desert at the rhisosphere layer of the date palm (Tamietti and Pramotton, 1990). Other samples were taken from the region of Boumerdes located in the central part of northern Algeria, from rhisosphere layer of wheat (Fig. 1).

\section{Isolation and Phenotypic Characterization of Bacterial Isolates}

Ordinary nutrient agar (GN) medium, $\mathrm{pH} 7.2$ was used for isolation bacterial strains. $0.1 \mathrm{~mL}$ of $10-1$ to 10 5 dilutions was seeded on the surface of isolation medium. The bacterial colonies obtained after incubation at $32^{\circ} \mathrm{C}$ for $48 \mathrm{~h}$ underwent purification. The obtained strains were then stored at $-20^{\circ} \mathrm{C}$ using glycerol $(20 \%$, $\mathrm{v} / \mathrm{v})$ as cryo-protector.

Identification of bacterial genera was based primarily on the study of several macroscopic characters (the colonies type) and microscopic examinations (the form of bacterial cells and their mobility). The characterization of isolates needed physiological traits (highlighting the respiratory type, presence and position of spores and type of Gram) and biochemical (catalase, oxidase, nitrate reductase, levane sucrase, arginine di hydrolase, Voges Proskauer reaction (VP), degradation of certain substrates, gelatin, starch, casein, urea, indole, sorbitol, mannitol, citrate, tartrate and the production of lipase) (Bergey et al., 1974; Dong and Cai, 2001; Guiraud, 2003).

\section{Molecular Identification}

The molecular study concerns the 8 best performing strains, those which gave the best results on the migratory locusts for the strains isolated from Adrar and on the wax moth for the strains isolated Boumerdes.

The 16S rRNA gene was amplified in three overlapping fractions with the following universal bacterial primers:

\begin{tabular}{llll}
\hline Primer & Sequence & Fragment & Size \\
\hline 16S1FOR_0008MF & AGAGTTTGATCATGGCTCAG & $16 \mathrm{~S} 1$ & 832 bp \\
16S1REV_0800M R & ACCAGGGTATCTAATC & & \\
16S2FOR_0514MF & GTGCCA GCAGCCGCGGTA & $16 \mathrm{~S} 2$ & 599 bp \\
16S2REV_1073M R & CACGAGCTGA CGA CA & $16 S 3$ & 805 bp \\
16S3FOR_0775MF & GAGCRAACA GGATTAG & & \\
16S3REV_1540M R & AAGGAGGTGATCCAACCGCA & \\
\hline
\end{tabular}

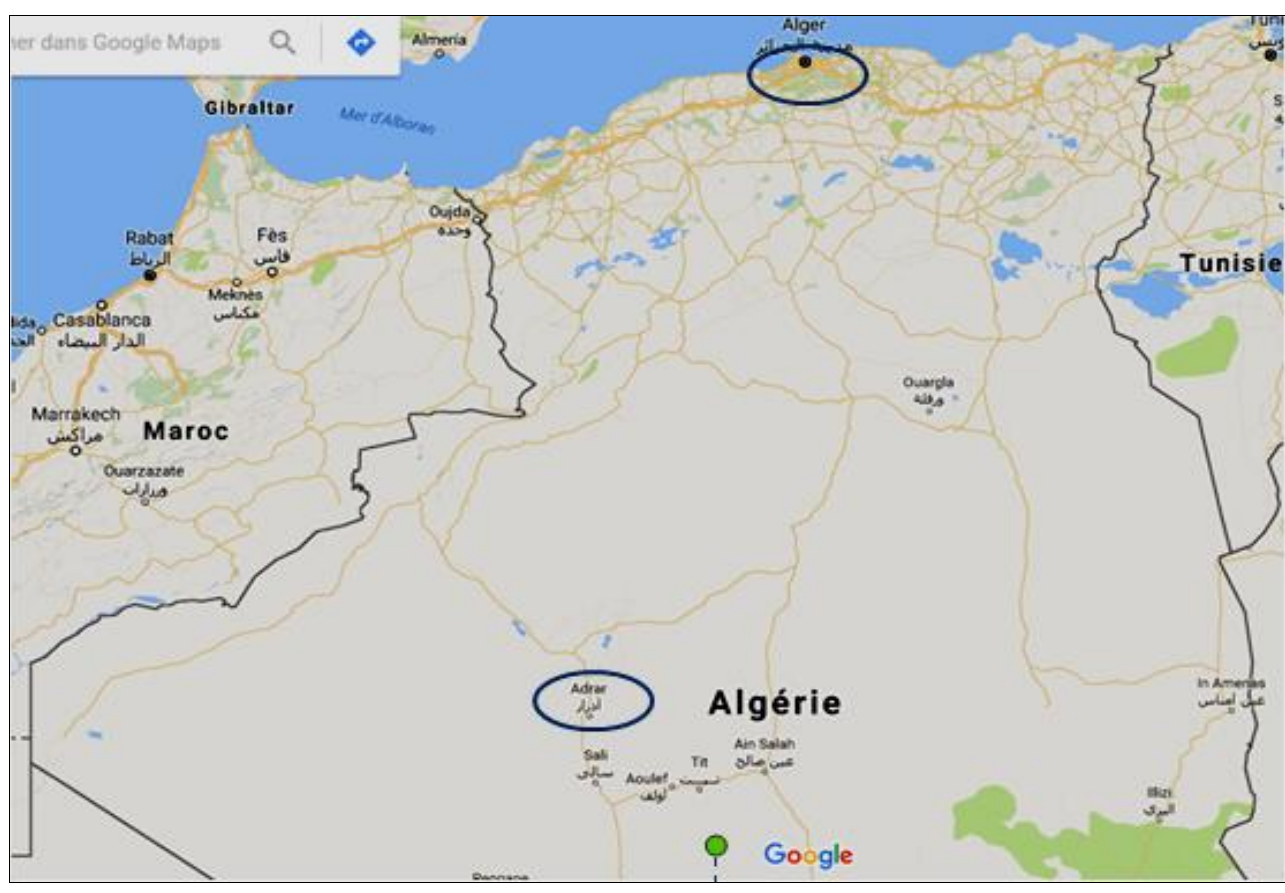

Fig. 1: Geographical situation of the sampling site 
The Forward primers (FOR) were tailed by the M1320FOR (CTGTAAAACGACGGCCAGT) primer whereas the Reverse ones (REV) by the M13-26REV (AGGAAACAGCTATGACCATG). Two colony PCR trials were performed per sample and per fragment and the obtained amplicons were run on agarose gel, cleaned-up and Sanger sequenced. Sanger sequencing was performed using the BigDye v3.1 chemistry on 3730XL machines (Applied Biosystems; www.appliedbiosystems.com). All obtained amplicons were sequenced from the forward and reverse directions using the universal primer-tailing of the $16 \mathrm{~S}$ amplification primers. The sequences were base called status with the software program Sequencing Analysis v.5.2 (Applied Biosystems; www.appliedbiosystems.com). All generated chromatograms were assembled per sample using the TraceEditPro software (Ridom Bioinformatics; http://www.ridom.de/traceedit/). The consensus sequences were analyzed by human expert for base calling errors and IUPAC code was applied for any mixed position (originating from the presence of several copies of the 16S rRNA gene for one species). The primer sequences chromatograms were manually trimmed and the resulting consensus sequences were exported in FASTA format. The obtained FASTA consensus sequences were analyzed by similarity searches with BlastN/Megablast against the nonredundant nucleotide database of GenBank (NCBI GenBank; http://blast.ncbi.nlm.nih.gov). Further on, the degree of statistical support for the branches was determined by 1000 bootstrap replicates. The maximum likelihood trees were estimated by using the rapid bootstrap option (100 replicates) (Tamura et al., 2011).

\section{Results}

\section{Phenotypic Characterization of Isolates}

20 bacterial strains were isolated from soil in the region of Boumerdes (coastal region located in the center of Algeria) with a total of 21 bacterial strains isolated from Adrar region (Sahara Desert, Algeria). Appearance of the colonies obtained on agar was very variable. The isolates were aerobic, mobile and with a positive catalase. Microscopic observation permitted their division into two groups, the first consisted of long rods, Gram positive and form a propertied sporal shape and the second contained short Gram negative rods and which non sporulating.

The isolates carrying the $\mathrm{B} 1$ and $\mathrm{B} 2$ codes provide well-isolated colonies, broad, smooth, flat, circulars, cream color with irregular edges. Observation under the light microscope, has shown that the two strains are Gram positive and are long stick shaped with square end.
Malachite green staining revealed that both isolates have a spore form. The spore has an oval shape nondeforming center position. Moreover, the two isolates B1 and B2 have shown positive results for the test of catalase, nitrate reductase and mannitol-mobility. The results of the pyruvic acid derivatives appeared positive for the Voges Proskauer reaction and the two isolates show a positive response for the hydrolysis of starch, gelatin and casein.

This isolates have all the cultural characteristics of the genus Bacillus already described by Brossard and Terry (1984) and Euzeby (2007).

Cultural characteristics on GN of the strains B3, B4 and B6 showed generally bacterial colonies whose contour was with a regular staining often beige cream. The elevation was convex for all strains with a glossy smooth appearance and varying diameters 1 to $2 \mathrm{~mm}$ after $24 \mathrm{~h}$ of culture. The bacterial strain B5 had smooth medium-sized colonies with an irregular edge. Moreover, the strains B5 and B6 showed positive results for some tests like nitrate reductase and mannitol. The strain B3 showed a positive result for the tests of mannitol and citrate. However, almost all strains B3, B4, B5 and B6 expressed negative results towards hydrolysis test of indole.

\section{Molecular Characterization}

In the present study, three bacterial genera Bacillus, Pseudomonas and Enterobacter were selected where the main members of the entomopathogenic bacteria belong to these genera (Greathead et al., 1994).

The selected strains B1, B2, B3, B4, B5 and B6, were isolated from Adrar (Algerian desert) and on the other side strains $\mathrm{H} 1$ and $\mathrm{H} 2$ were isolated from Boumerdes (Algerian coast).

The 16S rDNA sequences of the three strains B1, B2 and B5 were obtained with 1504, 760 and 1504 nucleotides and stored in the database EMBL/EBI under reference accession numbers HE799656, HE805963 and HF911367, respectively. Sequence analysis of two strains B1 and B2 has shown they are affiliated to the genus Bacillus (the family of Bacillaceae) showing very high sequence identity (99\%) with the strains Bacillus thuringiensis (NR_043403), Bacillus cereus AM7 (JQ435684), Bacillus weihenstephanensis (NR_024697.1) and Bacillus mycoides (NR_036880). Otherwise, the strain B5 showed a high sequence identity (99\%) with the closely related type strains of Bacillus species, $B$. anthrancis strain Ames, B. cereus strain $\mathrm{HN}$ and $B$. thuringiensis strain CMBLBT-5), which indicated that this strain can belong to one of these species. Moreover, the strains $\mathrm{H} 1$ isolated from the region of Boumerdes is identified as Bacillus strain H1 (LT547812) with a percentage of similarity (99\%) with Bacillus thuringiensis strain Se13 (KX959986) (Table 1). 
The rDNA $16 \mathrm{~S}$ sequences of the named strains B3, $\mathrm{B} 4$ and $\mathrm{B} 6$ were recorded in the EMBL/EBI data bank under the accession numbers HF911369, HF911366 and HF911368, respectively. The phylogenic analysis showed that the strains B3 and B4 had a sequence identity higher than $98 \%$ with those of the genus Pseudomonas. A significant similarity (based on partial 16RNAr sequence) for possible species relatedness (99\%) was found with the validly described species $P$. fragi strain JCM5420, P. syringae isolate Lz4W and P. psychrophila strain HA-4. The distance matrix indicated that strains B3 and B4 might belong to one of these species (Table 2). Further, the strain B6 was similarly closed to the species Enterobacter ludwigii strain EN119 and E. aerogenes strain MDAZTVIIIR105a with $99 \%$ of sequence identity. The strain $\mathrm{H} 2$ from the northern Algeria is identified as Delftia strain $\mathrm{H} 2$ (LT547813), with $100 \%$ similarity to Delftia lacustris strain: 6bw_2 (LC191530) (Table 2).

Finally, the four strains are in the same cluster as that of Bacillus thuringiensis (NR_043403) and Bacillus cereus AM7 (JQ435684), the most widely used entomopathogenic bacteria in the world. The other strains are distributed in different clusters (Fig. 2).

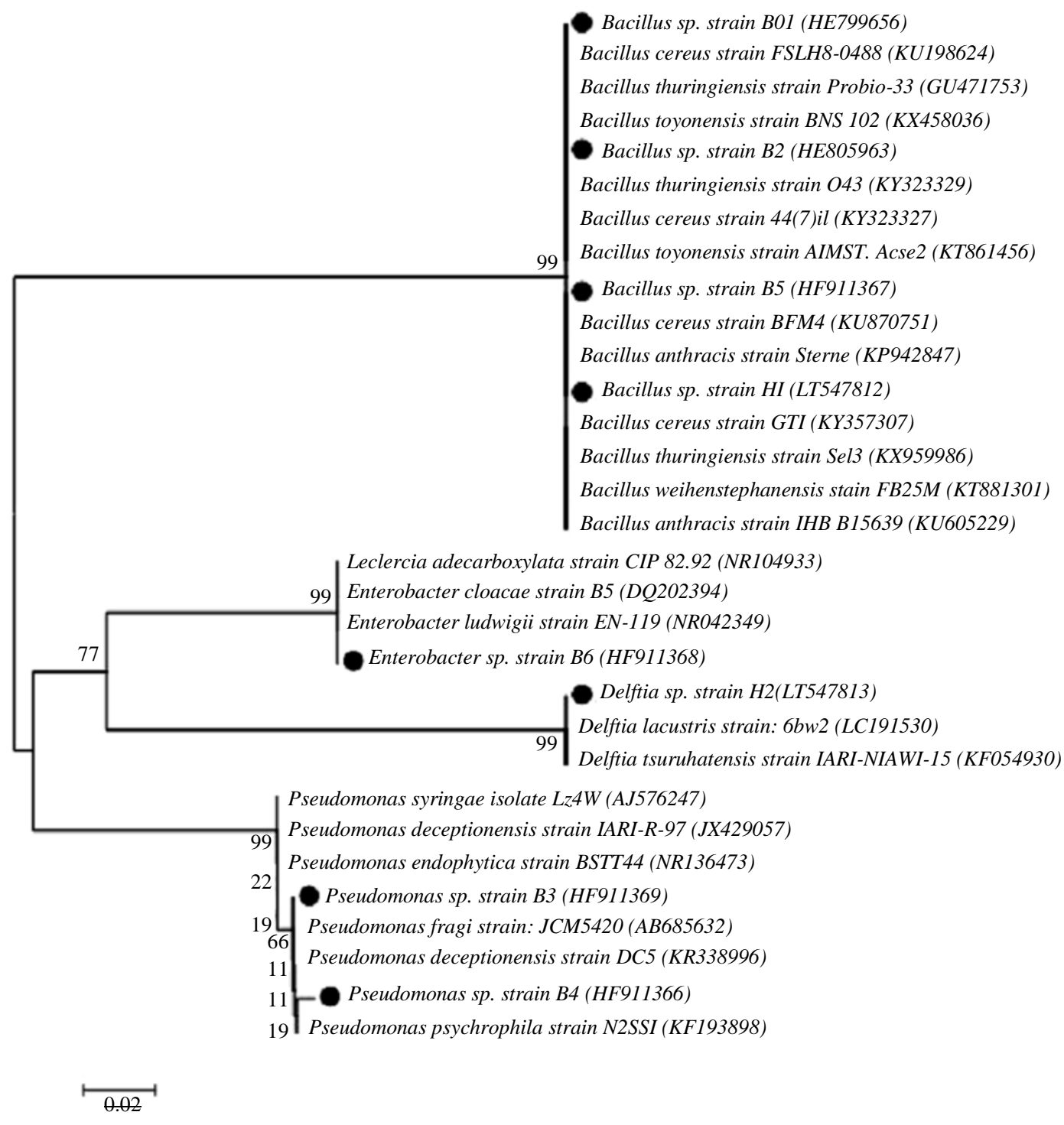

Fig. 2:Dendrogram indicating the position of the strains B1, B2, B3, B4, B5, B6, H1 and H2 (black circles) based on their 16S rDNA sequences. The tree was constructed using the neighbour-joining method. The sequence data used for the following strains were obtained from the sequences collected from Genbank database. The values at the tree nodes indicate percentages of recur- ring branches (1000 bootstraps for resampling) 
Table 1: Percentage identity to sequence of 16S rDNA of the strains B1, B2, B5 and H1 with some species

\begin{tabular}{llc}
\hline Isolated strain & Similar strains & Identity (\%) \\
\hline Strain B1 & & \\
$(1504 \mathrm{pb})$ & $\begin{array}{l}\text { Bacillus cereus strain FSL H8-0488 (KU198624) } \\
\text { Bacillus thuringiensis strain Probio-33 (GU471753) } \\
\text { Bacillus toyonensis strain BNS 102 (KX458036) }\end{array}$ & 99 \\
Strain B2 & Bacillus thuringiensis strain O43 (KY323329) & 99 \\
$(760 \mathrm{pb})$ & Bacillus cereus strain 44(7)il (KY323327) & 100 \\
& Bacillus toyonensis strain AIMST. Acse2 (KT861456) & 100 \\
Strain B5 & Bacillus cereus strain BFM4 (KU870751) & 100 \\
$(1504 \mathrm{pb})$ & Bacillus anthracis strain Sterne (KP942847) & 99 \\
& & 99 \\
Strain H1 & & 99 \\
$(806 \mathrm{pb})$ & Bacillus cereus strain GT1 (KY357307) & 99 \\
& Bacillus thuringiensis strain Se13 (KX959986) & 99 \\
& Bacillus weihenstephanensis strain FB25M (KT881301) \\
& Bacillus anthracis strain IHB B 15639 (KU605229) & 99 \\
\hline
\end{tabular}

Table 2: Percentage identity to sequence of $16 \mathrm{~S}$ rDNA of the strains B3, B4, B6 and $\mathrm{H} 2$ with some species required parameters are missing or incorrect

\begin{tabular}{|c|c|c|}
\hline Isolated strain & Similar strains & Identity (\%) \\
\hline \multicolumn{3}{|l|}{ Strain B3 } \\
\hline \multirow[t]{4}{*}{$(1204 \mathrm{pb})$} & Pseudomonas fragi strain: JCM 5420 (AB685632) & 100 \\
\hline & Pseudomonas eceptionensis strain DC5 (KR338996) & 100 \\
\hline & Pseudomonas syringae isolate Lz4W (AJ576247) & 100 \\
\hline & Pseudomonas deceptionensis strain IARI-R-97 (JX429057) & 100 \\
\hline \multicolumn{3}{|c|}{ 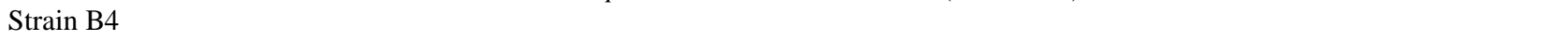 } \\
\hline \multirow[t]{3}{*}{$(538 \mathrm{pb})$} & Pseudomonas deceptionensis strain DC5 (KR338996) & 99 \\
\hline & Pseudomonas psychrophila strain N2SS1 (KF193898) & 99 \\
\hline & Pseudomonas endophytica strain BSTT44 (NR_136473 & 99 \\
\hline \multirow{4}{*}{$\begin{array}{l}\text { Strain B6 } \\
\text { (1492 pb) }\end{array}$} & & \\
\hline & Enterobacter ludwigii strain EN-119 (NR_042349) & 99 \\
\hline & Leclercia adecarboxylata strain CIP 82.92 (NR_104933) & 99 \\
\hline & Enterobacter cloacae strain B5 (DQ202394) & 99 \\
\hline \multirow[t]{2}{*}{$\begin{array}{l}\text { Strain H2 } \\
(817 \mathrm{pb})\end{array}$} & Delftia lacustris strain: 6bw_2 (LC191530) & 100 \\
\hline & Delftia tsuruhatensis strain IARI-NIAW1-15(KF054930 & 100 \\
\hline
\end{tabular}

\section{Discussion}

Bacteria represent the most commercially successful entomopathogenic microbial group, with most commercialized insecticides containing Gram-positive bacteria in the Bacillaceae family (De Bortoli and JuratFuentes, 2019).

In fact our study allowed us to isolate, 20 bacteria from soil cultivated in the region of Boumerdes and with a total of 21 bacterial strains from the Adrar region. After carrying out the efficacy tests against 2 insect pests; Locusta migratoria and Galleria mellonella, 8 potentially interesting strains were identified based on their genetic traits. Partial sequencing of ARN16S. allowed to affiliate 4 strains to the genus Bacillus, 2 strains to the genus Pseudomonas, 1 strain to the genus Enterobacter and one strain to the genus Delfetia. The first 3 genera are known by their entomopathogenic effect (Greathead et al., 1994) but for the last one no study has demonstrated its insecticidal efficacy.
Entomopathogenic spore forming bacteria, most notably Bacillus thuringiensis (Bt), are the most widely used Microbial Pest Control Agents (MPCA). The broad spectrum of susceptible hosts, production on artificial media and ease of application using conventional equipment have resulted in widespread use against several insect pests in crops, forest and aquatic habitats (Lacey and Siegel, 2000).

Indeed, the majority of bacteria of the genus Bacillus live in the soil or they persist with their spores. These are bacteria from land who derive their nutritional needs from an organic matter, nitrogen and minerals present in the soil (Brossard and Terry, 1984; Ashnaei et al., 2009).

Presence of Pseudomonas bacteria in the rhizosphere can be explained by their rapid growth, ubiquitous nature and ability to adapt to various environmental conditions, which was reported in many studies (Bossis et al., 2000). The facility of in vitro culture and the ability of some species of this genus of bacteria to produce antibiotics and siderophores in case 
of iron deficiency confer special characters in the biological control (Mamoun and Olivier, 1989).

Finally, the complete $16 \mathrm{~S}$ rDNA sequence analysis and DNA: DNA hybridizations are suggested for an extensive study for the identification of the obtained isolated strains.

\section{Conclusion}

As part of our study, sustainable use of rhizobacteria has been suggested to be an eco-friendly and cost-effective approach which increases crop yields and directly or indirectly protects plant from pathogens and the most redoubtable pests including the two pests having been the subject of our study, L. migratoria and G. mellonela.

\section{Acknowledgment}

The authors gratefully acknowledge the "Direction Générale de la Recherche Scientifique et du Développement Technologique (DGRSDT)" of the Algerian Ministry of Higher Education and Scientific Research, and thank Prof. Amina Khemili for her advice and careful reading.

\section{Author's Contributions}

Oulebsir-Mohandkaci Hakima: Participated in all experiments, coordinated the data-analysis and contributed to the writing of the manuscript.

Benzina Farida: Participated in the experimental study, re-wrote and edited major sections of the manuscript.

Khemili-Talbi Souad: Participated in the phylogenetic study, wrote specific sections and edited the final version of the submitted manuscript.

Mohammedi Arezki and Halouane Fatma: Designed and optimized the research plan and organized the study.

Hadjouti Ryma: Analyzed the data.

\section{Ethics}

The present paper is an original work with no conflict of interest.

\section{References}

Ashnaei, S.P., T.A. Sharifi, M. Ahmadzadeh and K. Behboudi, 2009. Interaction of different media on production and biocontrol efficacy of Pseudomonas fluorescens P-35 and Bacillus subtilis B-3 against gray mould of apple. J. Plant Pathol., 9: 65-70.

Benzina, F., H. Oulebsir-Mohandkaci, M. Belaid, H. Irnatene and S. Mammeri, 2017. Isolation of entomopathogenic bacteria from larvae of a lepidopteran specie; Galleria mellonella and study of their insecticidal effect. Agric. Forestry, 63: 59-68. DOI: 10.17707/Agricultforest.63.4.06
Bergey, D.H., R.G. Buchanan and N.E. Gibbons, 1974. Bergey's manual of determinative bacteriology. 1st Edn., Williams and Wilkins Co, Baltimore, pp: 272.

Bossis, E.P., X. Latour and L. Gardan, 2000. The taxonomy of Pseudomonas fluorescens and Pseudomonas putida: Current status and need for revision. Agronomie, 20: 51-63.

Brossard and Terry, 1984. Bactériologie Systématique (Systematic Bacteriology). 1st Edn., Ed.C.R.D.P, Lyon, pp: 220.

De Bortoli, C.P. and J.L. Jurat-Fuentes, 2019. Mechanisms of resistance to commercially relevant entomopathogenic bacteria. Curr. Opin. Insect Sci., 33: 56-62. DOI: 10.1016/j.cois.2019.03.007

Dong, X.Z. and M.Y. Cai, 2001. Manual of the identification of general bacteria. Scientific Press, Beijing.

Euzeby, J.P., 2007. Dictionnaire de bacteriologie vétérinaire. (Veterinary Bacteriology dictionary). www.bacdico.net

Greathead, D.J., C. Kooyman, M.H. Launois-Luong and G.B. Popov, 1994. Les Ennemis Naturels des Criquets du Sahel. 1st Edn., Montpellier, France, pp: 85.

Guiraud, J.P., 2003. Microbiologie Alimentaire; Application à L'étude des Principaux Groupes Microbiens. 1st Edn., DUNOD, pp: 651.

Jaronski, S.T., 2010. Ecological factors in the inundative use of fungal entomopathogens. BioControl, 55: 159-185. DOI: $10.1007 / \mathrm{s} 10526-009-9248-3$

Lacey, L.A. and J.P. Siegel, 2000. Safety and ecotoxicology of entomopathogenic bacteria.

Mamoun, M. and J.M. Olivier, 1989. Dynamique des populations fongiques et bactériennes de la rhizosphère des noisetiers truffiers. II. Chélation du fer et répartition taxonomique chez les Pseudomonas fluorescents. Agronomie, 9: 345-351.

Oulebsir-MohandKaci, H., S. Talbi-Khemili, S. GanaKebbouche and B. Doumandji-Mitiche, 2016. Antagonistic activity of two Bacillus sp. Strains isolated from an algerian soil towards the migratory locust Locusta migratoria (linnaeus 1758). Int. J. Agric. Forestry, 62: 145-154.

Sharma, L., I. Oliveira, L. Torres and M. Guilhermina, 2018. Entomopathogenic fungi in Portuguese vineyards soils: Suggesting a 'Galleria-Tenebriobait method' as bait-insects Galleria and Tenebrio significantly underestimate the respective recoveries of Metarhizium (robertsii) and Beauveria (bassiana). MycoKeys, 38: 1-23.

DOI: $10.3897 /$ mycokeys.38.26790

Sharma, L., N. Bohra, R.K. Singh and M. Guilhermina, 2019. Potential of Entomopathogenic Bacteria and Fungi. In: Microbes for Sustainable Insect Pest Management, Khan, M. and W. Ahmad (Eds.), Springer, Cham, pp: 115-149. 
Singh, B.N, M.V. Singh Rajawat, A. Hidangmayum and W.A. Ansari, 2019. Importance and Utilization of Plant-Beneficial Rhizobacteria in Agriculture. In: Microbial Interventions in Agriculture and Environment, Singh, D. and R. Prabha (Eds.), Springer, Singapore, pp: 171-187.

DOI: 10.1007/978-981-32-9084-6_8

Tamietti, G. and R. Pramotton, 1990. La réceptivité des sols aux fusarioses vasculaires: Rapports entre résistance et microflore autochtone avec référence particulière aux Fusarium non pathogènes. Agronomie, 10: 69-76.

Tamura, K.D., G. Peterson, N. Peterso, G. Stecher and M. Nei et al., 2011. MEGA5: Molecular evolutionary genetics analysis using maximum likelihood, evolutionary distance and maximum parsimony methods. Mol. Biol. Evol., 28: 27312739. DOI: $10.1093 / \mathrm{molbev} / \mathrm{msr} 121$
Vega, F.E., N.V. Meyling, J.J. Luangsa-Ard and M. Blackwell, 2012. Fungal Entomopathogens. In: Insect Pathology, Vega, F.E. and H.K. Kaya (Eds.), Academic Press, San Diego, pp: 171-220.

Zimmermann, G., 1986. The 'Galleria bait method' for detection of entomopathogenic fungi in soil. J. Applied Entomol., 102: 213-215.

DOI: 10.1111/j.1439-0418.1986.tb00912.x 